\title{
A fotografia como jogo interespacial
}

\section{Jefferson Fernandes Alves}

\section{Resumo}

Este artigo aborda a fotografia como jogo interespacial na perspectiva de explicitar as relações espaciais como um dos aspectos constituidores do conhecimento produzido através da fotografia

Palavras-chave: Fotografia, Relações Espaciais, Conhecimento.

\section{Abstract}

This article accost the photograph like game inter space in a perspective to explain the space relations as an constituent aspect from produced knowledge by photograph.

Key words: Pholograph, Space Relations; Linowledge. 
"Se existe na fotografia uma força viva irresistível, se nela existe algo que, a meu ver, depende da ordem de uma gravidade absoluta - e que é tudo sobre o que este livro gostaria de insistir-,é bem isso: com a fotografia, não nos é mais possível pensar a imagem fora do ato que a faz ser." (DUBOIS, 1998, p. 15. Grifo do autor).

Essas são as primeiras palavras que Dubois (1998) enuncia no esforço argumentativo de explicitar sua tese: a natureza epistêmica da fotografia, calcada em sua configuração indicial. Considerando a imagem fotográfica como imagem-ato, inclui no processo imagético tanto a produção como a contemplação, tanto a feitura como o produto, tanto o sujeito que fotografa como as coisas fotografadas e aqueles que a lêem. Nesse sentido, essa dimensão processual da imagem fotográfica está na gênese da construção de modos de ver e de pensar as relações que estabelecemos com o mundo e com os outros sujeitos.

Tais modo de ver e de pensar as relações que são estabelecidas com o mundo e com os outros sujeitos dizem respeito, simultaneamente, à representação figurada do espaço e à própria espacialidade fotográfica, uma vez que, como nos diz Dubois (1998), "com a fotografia não nos é mais possivel pensar a imagem fora do ato que a faz ser." Dessa maneira, propomos um percurso teórico pelos meandros da própria fotografia como forma de explicitarmos sua condição de jogo interespacial.

Antes de mais nada, é preciso esclarecer que o seu ardil de transcodificação da tridimensionalidade do real para a bidimensionalidade do papel traduz um itinerário que remonta à perspectiva central e à câmera obscura, adotadas pelos artistas renascentistas. Assim, formalmente, as primeiras experiências de Niépce ${ }^{1}$ demarcam um percurso oculocêntrico que deságua nas primeiras décadas do século XIX. As primeiras imagens reveladas converteram-se naquilo que Frade (1992) chama de figuras de espanto pelo fato de que descortinava uma gama de aplicações e de descobertas visuais de universos nunca vistos, demarcando um novo patamar cultural da visualidade.

Esse novo patamar cultural, calcado na representação figurada das coisas, ao mesmo tempo que abalou e influenciou os ditames pictóricos oitocentistas, provocou a miniaturização do real e, em consequiência, sua posse simbólica. Monumentos, paisagens, pessoas, lugares distantes passam a caber nas mãos dos leitores-proprietários, materializando aquilo que Harvey (1993) designa de contração do tempo-espaço.

O fenômeno da relativização espacial da realidade em que o distante se manifesta na proximidade do contato físico com sua representação, 
fundamenta as reflexões de Benjamin (1988) a respeito da natureza reprodutivel da fotografia como destruidora da aura, insígnia da sacralidade do original enquanto manifestação do longínquo por mais próximo que esteja. É precisamente pela sua condição de "cópia", de ente reprodutivel que Benjamin interpreta a fotografia como um expediente iconoclasta face às representações pictóricas, portadoras da unicidade demiúrgica.

A característica da reprodutibilidade imagética como um dos componentes técnico-mecânicos da folografia permitiu a proliferação do registro fotográfico como um dos procedimentos representacionais mais requisitados pela burguesia que não podia custear a produção pictórica, convertendo-se em signo estandartizador de sua condição social e da imagem que esta classe fazia de si mesma,

Pois 'fazer, tirar o seu retrato' era um daqueles actos simbólicos pelos quais os indivíduos da classe social ascendente tornavam visível para si mesmos e para os outros a sua ascensão e se classificavam entre os que gozavam de consideração social. (FREUND, 1995, p. 25).

A popularização da fotografia, por sua vez, manteve estreita relação com o aprimoramento técnico do processo fotográfico e da correlata simplificação dos equipamentos, tendo na compactação maquínica proposta por George Eastman, o seu grande marco. Lançada em 1888, a Kodak $n^{\circ} 1$, ao mesmo tempo em que aglutina e comprime todo o saber físico-químico do fotográfico da época, permite a ruptura desse saber, na nıedida em que exime o fotógrafo ocasional das etapas anteriores e posteriores do processo fotográfico. O slogan da Kodak $\mathrm{n}^{\circ}$ l é emblático: você aperta o botão e nós faremos o resto.

Tal slogan estandartizou a divisão social do saber fotográfico em curso, à proporção que distribuiu e separou, técnica e socialmente, os saberes que, até então, condensavam-se no ato fotográfico, uma vez que o fotógrafo necessitava de conhecimentos físico-químicos necessários para operacionalizar todo o ciclo fotográfico. Com o aprimoramento maquínico. esse ciclo é rompido do ponto de vista da manipulação individual, em razão de que os saberes físico-químicos não são mais requeridos por aquele que fotografa. Tal ciclo é recomposto socialmente, pelo fato de que vai se constituindo, mercadologicamente, em uma rede de empresas e serviços que se ocuparão das múltiplas partes que o compõem.

Nesse caso, irradia-se a prática fotográfica. mas condicionada pela divisão técnico-social do trabalho no campo da fotografia, separando as etapas de preparação e revelação do registro fotográfico propriamente dito. Por outro lado, essa divisão permitiu a sintetização e aprimoramento das etapas que antecedem e sucedem o registro fotográfico, favorecendo sua 
apropriação técnica e cognitiva por aqueles que se interessavam èm ter acesso a todo o ciclo, sendo fotógrafo profissional ou não.

Por conseguinte, essa divisão, que acompanha a própria proliferação de imagens e de máquinas que a produz, engendra expectativas de leitura e de produção diversas que ultrapassam as motivações meramente artísticas, irrandiando-se através de práticas cotidianas de interações. De uma forma ou de outra, as pessoas, os eventos, as atividades, os lugares, as cenas vistas, comemoradas, celebradas e/ou apreciadas, são e devem ser eternizadas pelo registro fotográfico.

Dessa maneira, a fotografia ingressa no cotidiano das pessoas como processo e resultado de novas práticas culturais do olhar, cujos elementos sintáticos, além de expressar determinados saberes inerentes à linguagem fotográfica, proporcionam a passagem interespacial da tridimensionalidade do real para a superfície plana do suporte representacional.

\section{Fotografia: o jogo entre os espaços}

Essa passagem consubstancia a natureza interativa da fotografia $\mathrm{em}$ razão de que o registro fotográfico exige uma interface entre o protagonista do registro e aquilo que está sendo registrado. Do ponto de vista conceitual, Dubois (1998) designa de espaço referencial tudo aquilo que está sujeito ao olhar seletivo da máquina fotográfica. Em outros termos, a realidade sujeita ao recorte fotográfico, desencadeador do espaço fotográfico.

Para Dubois (1998), a fotografia como uma espacialidade específica (o espaço fotográfico) contempla dois espaços imbricados, cuja evocação distinta é meramente didática. O primeiro corresponde ao espaço representado entendido como a mensagem, o conteúdo semântico da imagem fotográfica; e o segundo, é o espaço de representação que diz respeito à materialidade do suporte, a superfície na qual a imagem é impressa. A articulação de ambos permite a apreensão da imagem fotográfica como uma experiência espacial dúplice, a qual é identificada por Aumont (1995, p. 61) como inerente à dupla realidade da imagem:

[...] percebemos simultaneamente essa imagem como fragmento de superfície plana e como fragmento de espaço tridimensional: é esse fenômeno psicológico fundamental que se chama dupla realidade perceptiva das imagens, ou, por abreviação, dupla realidade das imagens.

No processo transcodificador do espaço referencial para o espaço fotográfico, DUBOIS (1998) não esclarece a inserção espacial do sujeito que promove o registro fotográfico. No nosso entendimento, esse sujeito está 
imerso na própria espacialidade referencial, cujas interações nela estabelecidas. desencadeiam estímulos fotográficos provocadores de uma descontinuidade perceptiva, mediada pelo olhar maquínico.

Em outros termos, o acionamento da máquina, como um procedimento que antecede o próprio registro, já instaura um processo seletivo do real, demarcando, simultaneamente, a vinculação e a ruptura do olhar fotográfico face à imensidão do espaço referencial, lançando o fotógrafo e aquilo que está sendo fotografado para uma outra espacialidade que se ergue nos interstícios da tomada fotográfica, a qual denominamos espaço de fotografação.

Marcado pela paradoxalidade de pertencimento e exclusão do espaço referencial, o espaço de fotografação constitui um espaço dentro de outro espaço, cujas relações são orquestradas por uma encenação na qual os ritmos, os deslocamentos e os tempos estariam subjugados aos caprichos da fixação imagética de situações e eventos que são duplamente vivenciados como experiência imediata e como possibilidade de eternização.

A fotografia como prática cultural assegura o surgimento intersubjetivo do espaço de fotografação como desdobramento. sobreposição e interferência no espaço referencial. Bailes, festas, batizados. casamentos. aniversários, cenas e fenômenos do cotidiano e da vida sócio-política, sempre são marcados por uma intromissão. freqüentemente consentida e aceita socialmente, do fotógrafo, cuja posse da máquina permite-lhe atravessar e interferir no espaço referencial.

Essa interferência, planejada ou não. suscita determinados arranjos viso-corporais que ratificam o espaço de fotografação como inerência e separação do espaço referencial e que antecede a própria consumação do ato fotográfico. Abaixar-se. erguer-se. deslocar-se, recuar. parar são al gumas das marcas coreográficas que o corpo do fotógrafo encena e que. por alguns instantes, imobiliza-se para petrificar tudo aquilo que é visto pelo olhar maquínico. assumindo. muitas vezes, a própria prolagonização do evento que está sendo registrado.

Aos olhos das testemunhas oculares (incluindo o fotógrafo e os eventuais modelos), isso consiste na duplicaçāo do espaço referencial. pois contempla. a um só tempo, o evento em seu transcurso e a espacialidade construída pelo próprio ato fotográfico. a qual não apenas está contida em outro espaço, como um evento dentro do evento. mas assume. muitas vezes. um caráter de determinação do próprio transcurso do espaço referencial:

Diante de uma câmera. não há racalidade que permaneça intacta: tudo se altera. tudo se arranja. tudo concorre para a ordem ideal do monumento. Basta apenas que alguém penetre com uma câmera no interior de uma instituição qualquer e de repente aparecerá uma legião de faxineiros limpando o terreno: os móveis serĩo arrastados para a 
melhor disposição, peças e pessoas indesejáveis serão retiradas de cena, toda desordem - física, mental, social - será substituída por uma paisagem homogênea e asséptica; alguém colocará um vaso de flores em cima da mesa." (MACHADO, 1984, p. 54).

Cria-se, com isso, uma cisão que antecede e acompanha a própria ruptura entre campo visual e extra-campo. Trata-se de uma separação cognitiva e perceptiva que se efetiva entre a posição do fotógrafo no espaço e aquilo que deseja fotografar, reiterada pelo fato de estar por trás da câmera. Essa, por sua vez, ao mesmo tempo em que opera a ruptura instauradora da disjunção entre espaço referencial e espaço fotográfico, também separa, no espaço referencial, o lugar assumido pelo autor fotográfico, lançando-o para a (in) visibilidade do contra-campo.

Dessa forma, as designações de campo visual, extra-campo (ou forade-campo) e contra-campo traduzem as interfaces corporficadas nos espaços referencial, fotográfico e de fotografação como expressões de conteúdos sócio-interacionais mediados pela fotografia, as quais se plenificam nos diversos contextos de apreciação.

Se, até o momento, dedicamo-nos à apreensão dessas interfaces no que diz respeito ao registro fotográfico, não podemos obliterar que o processo interativo mediado pela imagem fotográfica implica os atos de apreciação como instância consolidadora do movimento de significação: produtor - obra - leitor.

Nesse sentido, Dubois (1998) designa o lugar apreciativo do leitor de espaço topológico por manter uma relação de continuidade entre o espaço fotográfico e o espaço referencial da imagem. A topologização da leitura fotográfica decorre de componentes físico-culturais que estão relacionados, simultaneamente, às experiências viso-corporais com a força gravitacional da terra e com a tradição figurativa impressa no fotográfico.

No primeiro caso, Luria (1991, p. 84) argumenta que a movimentação do ser humano e sua disposição ereta permite a apreensão dinâmica do espaço circundante onde,

Uns objetos estão situados acima de nós outros abaixo, uns são mais distantes, outros, mais próximos; uns estão à direita, outros, à esquerda. Nesse espaço assimétrico, as diferentes disposições espaciais dos objetos têm, freqüientemente, importância decisiva.

Esse caráter assimétrico do espaço percebido, em última instância, tem como referência o corpo humano face à força gravitacional da terra, sendo que as relações de profundidade, horizontalidade e verticalidade que estabelecemos com os fenômenos e com as outras pessoas, que se manifestam externamente no mundo e em relação a nós, também estão implicadas na fotografia, em seus processos de produção e de leitura. Quer seja na 
representação bidimensional da imagem, quer seja na varredura ocular do seu espaço interno, há sempre um movimento de continuidade e de ruptura em relação à tridimensionalidade do espaço referencial e do espaço do leitor.

Já no segundo caso, correspondente à figuratividade, o que sujaz às interpretações correntes da fotografia é o fenômeno da similitude baseado nas dimensões icônico-indicial da imagem em função de que esta procura manter relações de analogia e contigüidade com o espaço referencial. Abordando esse fenômeno, Dubois (1998) nomina de congruência a homologia instituída entre os espaços implicados no ato fotográfico:

E é essa adequação axial entre todos os espaços, essa congruência geral que organiza de fato todo nosso acordo espacial com a imagem. Ela é obtida essencialmente com base no ponto de vista de onde a foto é feita e pelo jogo desses embreantes de congruência que são os bordos do quadro. É o próprio ato da tomada que. por intermédio de um operador de representação estruturado ortogonalmente (o retângulo da janela), gera a homologia estruturante entre os quatro espaços. Porque a tomada se identifica com o nosso olhar (aqui está todo $o$ ato fotográfico), o espaço da foto parece "naturalmente" congruente com o espaço real, tal como a nossa percepção corrente capta. (DUBOIS, 1998, p. 213-214. Grifo do autor).

A manifestação "naturalmente congruente" da fotografia incorre em um aspecto refratador da imagem que é, justamente, o ocultamento da distinção interespacial por força, inclusive, da herança renascentista. Isto porque a consolidação do modelo figurativo calcado tanto na perspectiva central, como na câmara obscura, no retângulo áureo e nas objetivas, presente nas imagens técnicas, converteu-as em poderosos artefatos sociais de educação do olhar em que a representação da tridimensionalidade do real se "naturalizou" como fenômeno da correspondência homológica.

Nesse sentido, os atos cotidianos de leitura fotográfica orienta-se pela recuperação da congruência interespacial uma vez que a própria manipulação do artefato imagético pressupõe a correspondência ortogonal provocada pelo registro fotográfico em que o espaço fotográfico. como contemplador do conteúdo e do suporte. apresenta uma homologia estrutural das linhas em relação ao espaço referencial e ao espaço topológico do leitor.

Mas, se essa adequação axial referida por Dubois (1998) decorre, em última análise, do ponto de vista adolado pelo fotógrafo no ato do registro fotográfico, podemos afirmar que a experiência topológica não se restringe aos atos de leitura. Isso significa dizer que a observância das linhas ortogonais concorrentes para a congruência no momento da tomada fotográfica não 
apenas consagra o corte imagético do real, mas insinua sua percepção topológica por parte daquele que protagoniza esse.corte.

Observa-se um momento de leitura do espaço referencial em que a consideração da congruência importa na continuidade interpretativa dos espaços. De outra forma, a própria ruptura instaurada pelo recorte fotográfico pode ser acentuada, na medida em que o ato fotográfico relativize a congruência, gerando enquadramentos bizarros, tensos e oblíquos e "desnaturalizando" a aparente homologia entre o real e sua representação imagética.

\section{Nuances do jogo: o visto, o revisto e não visto}

Mesmo com o rompimento relativo da congruência no momento do registro fotográfico, são comuns, nos processos apreciativos da imagem, os movimentos compensatórios no suporte para alinhá-lo com as linhas fundamentais do espaço topológico de quem lê, considerando seu posicionamento perpendicular à horizontalidade da crosta terrestre. De qualquer forma, as articulações espaciais assinaladas como inerentes ao ato fotográfico são marcadas pelas relações de ruptura e de continuidade.

Se compreendermos, à luz de Dubois (1998), que o espaço fotográfico é construído como uma subtração de determinada parcela da infinitude do espaço referencial, constataremos que essa tensão relacional se manifesta 210 como intrínseca à fotografia. Um dos aspectos da leitura fotográfica que é posto em relevo é o fato de que a interpretação imagética orienta-se pela necessidade de recomposição do espaço referencial. Busca-se entender o contexto que a gerou, o entorno que não está explicitamente visível. Há um esforço perceptivo em identificar aquele que fotografou e os eventuais seres humanos fotografados.

É óbvio que tal recomposição não se presta à restauração da espacialidade que nutriu a representação imagética. A inexorabilidade do tempo consagra a ruptura instaurada. Entretanto, essa espacialidade é virtualmente reconstruída como forma de revelação de elementos que foram excluídos do fatiamento provocado pelo olho maquínico, como expediente compreensivo daquilo que foi selecionado imageticamente. Além disso, a interpretação daquilo que visivelmente se mostra no espaço fotográfico está condicionada, muitas vezes, à evocação virtual daquilo que foi deixado de fora do campo visual.

Essa tensão relacional descontinuidade/continuidade, que lança o leitor do espaço fotográfico ao espaço referencial, além de constituir-se em um estruturante de estratégia de leitura que evidencia a natureza testemunhal da imagem fotográfica como expediente ratificador que, a princípio, os 
ambientes e as pessoas existiram e estiveram sob a mira da máquina fotográfica, também, ratifica-se como intrínseco ao fotográfico:

Em outras palavras, o que uma fotografia não mostra é tão importante quanto o que ela revela. Mais exatamente, existe uma relação-dada como inevitável, existencial, irresistível - do fora com o dentro, que faz com que toda fotografia se leia como portadora de uma "presença virtual", como ligada consubstancialmente a algo que não está ali, sob nossos olhos, que foi afastado, mas que se assinala ali como excluído. (DUBOIS, 1998, p. 179. Grifo do autor).

Por conseguinte, do ponto de vista estético e epistêmico, a fotografia carrega, dentro de si, as marcas do ausente, reiterando as articulações interespaciais. Para uma aproximação e identificação de tais marcas, é preciso evocarmos algumas categorias espaciais inerentes à imagem fotográfica, já mencionadas mais acima. O campo visual como aquilo que se manifesta na imagem fotográfica e, portanto, sinônimo de espaço fotográfico. O extracampo como aquilo que é excluído pelo registro fotográfico. É o ausente que corresponde ao espaço referencial. E o contra-campo que diz respeito ao lugar assumido pelo fotógrafo no momento do registro imagético, o qual nos remete à constituição do espaço de fotografação como inserção e ruptura com o espaço referencial.

Do ponto de vista teórico, Dubois (1998) é quem assinala a presença virtual do extra-campo e, portanto, de fragmentos do espaço referencial, no espaço fotográfico. Ele identificou três categorias de indicadores que insinuam, no campo visual da imagem fotográfica, a presença virtual de espacialidades alijadas desse campo pelo corte maquínico.

Os indicadores de movimento e de deslocamento correspondem à primeira categoria que contempla artefatos (carros, carroças, objetos cilíndricos, etc) e seres vivos (pessoas e animais) que o estatismo do congelamento imagético propõe uma mobilidade para além do visível, como se dirigissem para as bordas do quadro, influenciando a apreciação do leitor que acompanharia, imaginativamente. o rompimento das fronteiras do campo visual.

Tais indicadores põem em relevo a própria condição petrificadora da fotografia, na medida em que o movimento é posto em causa como uma remissão ao extra-campo. De fato, o registro fotográfico ao mesmo tempo que se inscreve como um corte na continuidade movente do espaço referencial petrifica uma parcela deste na superfície medusiana do espaço fotográfico.

Esse estatismo como inerência da fotografia consagrou a pose pictórica como um componente característico de sua prática social. Dos primeiros registros e dos longos minutos de imobilização por conta das deficiências 
das superfícies fotossensíveis de então, a pose converteu-se em uma insígnia reiteradora da fixidez imagética. É nesse sentido que Machado (1984, p. 52) argumenta que a pose posterga-se, anacronicamente, com o próprio desenvolvimento técnico da fotografia: "A fotografia (tecnologia avançada) passa a conviver com a pose (armadura arcaizante), como se se estivesse tornado parasita de um organismo atrofiado".

Esse desenvolvimento técnico, por outro lado, permite o surgimento de emulsões mais rápidas, geradoras do instantâneo fotográfic ${ }^{22}$ ALMEIDA (1995, p. 40) argumenta que o instantâneo não apenas é acentuado pela existência da pose como, simultaneamente, ratifica que tudo está em pose, entrelaçando a mobilidade e o estático: “

$O$ instantâneo é a aceitação rendida de que tudo está em pose tal como a pose é a admissão charmosa do transitório.

“, fazendo com que as fotografias detenham o próprio movimento, imobilize-o por um olhar cada vez mais petrificador. Assim, os indicadores de movimento e deslocamento podem ser interpretados como expressões dessa captura, uma vez que a instantaneidade da imobilização expõe uma paradoxalidade do movimento em suspensão: "Em outras palavras, o instantâneo só nos restitui um único instante do movimento, imobilizado, na maioria das vezes capturado no apogeu de seu percurso." (DUBOIS, 1998, p. 182).

Desse modo, os indicadores já referidos podem ser descongelados pelo olhar do leitor que lhe restitui, virtualmente, a totalidade dos movimentos, a partir dos quais, recompõe-se o extra-campo como continuidade espacial necessária à essa restituição.

A segunda categoria assinalada por DUBOIS (1998) são os jogos do olhar. Segundo esse autor, o registro de retratos de pessoas, mais especificamente, a captura do olhar dos que são retratados, remetendo ao contra-campo, no qual se posiciona aquele que promove o registro:

Um fora-de-campo, portanto, que posiciona o operador explicitamente, que o integra mais ou menos como parceiro invisível, que designa seu lugar, que é o próprio lugar do olhar constitutivo da cena e do próprio campo. (DUBOIS, 1998, p. 183. Grifo do autor).

O olhar que mira o próprio olhar maquínico rompe a planura da imagem fotográfica e avança, denunciando sua profundidade relativa e o lugar autoral de seu registro. Não só isso. O olhar frontal do retrato, invariavelmente, se 
manifesta como a revelação do espaço topológico daquele que o aprecia. Dúplice processo de percepção. Aquele que apreende os estímulos imagéticos, é visto por um olhar que o encara do espaço fotográfico, revelando-lhe. Entreolhar, jogo mútuo entre quem vê e quem é visto, denunciando a fisionomia intersubjetiva da fotografia. denunciando as feiçem é visto.a do espaço fotogrnifesta como uma prescruçompanhar os olhares laterais que o remete ao extra-ca

Apesar de Dubois (1998) restringir os jogos do olhar apenas à relação de frontalidade como revelação virtual do contra-campo, a partir do qual desencadeia-se a enunciação imagética, é preciso não perder de vista o fato de que os retratos que ostentam olhares laterais, também, estão inseridos no referido jogo.

Nesse caso, a ruptura do campo visual não se daria apenas por um deslocamento frontal, mas pelo transbordamento lateral em que os olhares não contemplariam o vazio e sim, o ausente que se manifestaria no extracampo. No nosso entendimento, Dubois (1998) não considerou os olhares laterais como integrantes dos jogos do olhar, por considerá-los como definidores do extra-campo fílmico, sendo evocados para um exercício comparativo com o olhar frontal, intrínseco ao fotográfico.

Embora o olhar lateral (ou mesmo para cima e para baixo) do cinema esteja relacionado à mobilidade enunciativa, cuja sequiência é auxiliada por esse olhar, na medida em que auxilia a conversão do extra-campo em campo visual, não se reduza à imagem fílmica. Nesse sentido, no caso da fotografia. a mobilidade enunciativa não está na própria mídia, mas na capacidade interpretativa do leitor que procura preencher e acompanhar os olhares laterais que o remete ao extra-campo.

A terceira categoria que provoca as relações espaciais de dentro/ fora da imagem fotográfica é designada de cenário que corresponde a um conjunto de elementos - portas, janelas (entreabertas); fundos (duplos e de cena); espelhos; quadros, recortes - que, segundo ele, demarca a existência ou a indicação de espaços dentro do espaço (fotográfico): " $/ . . .1$ em suma, tudo o que pode indicar ou introduzir dentro do espaço homogêneo e fechado do campo fragmentos de outros espaços, em princípio contíguos e mais ou menos exteriores ao espaço principal." (DUBOIS. 1998. p. 187).

Dada a multiplicidade de elementos que provocam a evocação de espaços ausentes, Dubois (1998) divide essa categoria em quatro séries. A primeira delas é nominada de fora-de-campo por efeito de (re)centramento e diz respeito à introdução de quadros dentro do próprio quadro da representação. Trata-se da intromissão, intencional ou não, de molduras físicas sem nenhuma semantização que não advenha delas mesmas: 
[...] mas nada além de um quadro, quadro vazio, sem suporte interno próprio, desprovido de qualquer "conteúdo" representativo novo, não veiculando nem mesmo um fora-decampo particular propriamente dito, contentando-se finalmente com exercer uma função de localização enquadrante de uma parte do campo. (DUBOIS, 1998, p. 189. Grifo do autor).

Esse ardil estético de um quadro dentro de outro quadro tematiza a própria condição fatiadora da fotografia em razão de que propicia um "metadiscurso" por evidenciar a ruptura com o extra-campo. Desse modo, o quadro interno, ao recentrar o campo visual e construir um "extra-campo" relativo e visível, ratifica a ausência do extra-campo fundamental pela própria finitude de suas bordas.

A segunda série da categoria cenário é designada de fora-de-campo por fuga e diz respeito a passagens e recortes inerentes ao espaço referencial e que se manifestam no espaço fotográfico na perspectiva de assinalar as transições para espaços e cômodos não vistos, mas insinuados através de portas, janelas e múltiplas aberturas, as quais produzem a sensação de continuidade do espaço atando o campo visual à referencialidade do extracampo.

Nesses casos, o espaço fotográfico funciona como uma "caixa 214 cênica", a partir da qual se dimensiona essa continuidade. Isso implica na correspondência entre o contra-campo, definidor do olhar autoral, e a espacialidade topológica de quem observa essa "caixa cênica", a partir da identificação do ponto de vista adotado pelo registro fotográfico.

O problema da exterioridade virtual com relação ao campo coloca-se portanto aqui de certa maneira no interior do próprio quadro, em sua fieira, em sua fuga, na contigüidade espaçotemporal do representado fotográfico, na profundidade diegética do enunciado. (DUBOIS, 1998, p. 194).

Esse olhar topológico que enxerga o campo visual explicitado pelo espaço fotográfico, alinhado ao olhar enunciador, deflagrado do contracampo, promove uma exploração visual e virtual da profundidade imagética por deslocar-se na planura da imagem em busca da transposição das passagens oferecidas.

Esse alinhamento ocular é abordado por Machado (1984) como consubstanciador da natureza ideológica da fotografia, uma vez que o ponto de vista sugerido pela imagem, e toda sua carga estético-perceptiva herdada 
da perspectiva central, provoca um assujeitamento ao olhar alheio, em função de que não apreciamos a imagem através do nosso olhar. mas sim através do olhar de quem a produziu:

A construção em perspectiva renascentista nos dá sempre uma paisagem já vista e já dominada por um olhar; isso significa que quando vemos uma foto não é simplesmente a figura que nos é dada a olhar, mas uma figura olhada por outro olho que não o nosso. (MACHADO. 1984, p. 94. Grifo do autor).

Dessa maneira, o que é visto no campo visual, traduz as opções, valores e visões do sujeito que produziu a imagem. Nesse sentido, por trás do esforço naturalizador da figuração homológica da imagem fotográfica, há um olhar autoral que contribui para esse esforço, na medida que se (con)funde com o olhar do espectador.

Esse assujeitamento é relativo quando o olhar autoral é interpretado como uma visão motivadora (SCHAEFFER, 1992), a partir da qual o leitor da imagem constrói seu próprio olhar interpretativo, inclusive revelando as urdiduras da imagem e o lugar do contra-campo de quem a gerou.

A terceira série sugerida por Dubois (1998, p. 195) como integrante da categoria cenário é denominada de fora-de-campo por obliteração: " $/ .$. I trata-se de tudo o que vem introduzir, no campo de base enquadrado pela tomada, espaços neutralizantes de todas as formas, de todas as cores e de todas as naturezas [...]".

Corresponde a procedimentos, intencionais ou não. de encobrimento. apagamento, eliminação parcial, ranhura e omissão de determinadas informações visuais da fotografia. Podemos exemplificar, evocando as imagens em que os modelos aparecem com tarjas pretas (menores e testemunhas); em que as marcas corrosivas do tempo e dos fungos consomem sua integridade visual; em que os rostos são riscados, escondendo-se por trás de grafias raivosas; em que pedaços são rasgados ou recortados como índices de relações rompidas.

Essa ausência representativa expõe a própria natureza objetal da imagem fotográfica, bem como, os processos de sua enunciação. uma vez que provocam inquietações interpretativas com vistas ao preenchimento dos vazios, dos apagamentos e das rasuras que se enredam como indicação de um extra-campo provocado por ocultação e despedaçamento.

A quarta e última série apresentada diz respeito ao fora-de-campo por incrustração e corresponde à toda fotografía produzida a partir da 
utilização de espelhos ou de superfícies refletoras que, ao contrário, da obliteração, insere, agrega espaços externos à espacialidade do campo visual.

Em outras palavras, o fora-de-campo do espelho, na medida em que é uma representação total e não apenas uma pura opacidade, não se contenta com ocultar uma parte do espaço do campo (supressão), ele funciona aí também por adjunção, adição, inscrição de um espaço figurativo em um outro. (DUBOIS, 1998, p. 198)

Nesse caso, a ausência se faz presente fisicamente em decorrência da capacidade agregadora dos espelhos e das superfícies refletoras, revelando, dentro dos limites visíveis do espaço fotográfico, o enunciatário da imagem (auto-retrato, por exemplo), absorvendo, total ou parcialmente, o contracampo, da qual a enunciação é gerada. Essa capacidade de fusão interespacial diz respeito, também, à evocação visual do extra-campo em que se explicita não a autoria imagética, mas fragmentos do espaço referencial que não são selecionados diretamente pelo olho maquínico, e que são refletidos por aquilo que foi enquadrado.

Por exemplo, a fotografia da lateral de um carro pode nos revelar imagens "impressas" nos seus vidros ou nas suas portas. O próprio registro de espelhos (incluindo de carros), a partir de ângulos laterais, pode nos revelar pedaços da continuidade do espaço referencial que escapam à 216 seletividade da câmera fotográfica. Tais estratégias enunciativas, por acaso ou propositais, põe-nos diante de espaços rompidos que são costurados pela força representacional da imagem fotográfica.

É essa força representacional, que articula os múltiplos espaços, que nos permite interpretar a fotografia como um jogo. Um jogo que nos põe diante da re(a)presentação das espacialidades como construções sóciosimbólicas que contém e são contidas por conteúdos humanos, reveladores, em última instância, da processualidade da própria humanidade.

Na condição de um poderoso artefato social de educação do olhar, a fotografia se manifesta como um enredamento de interfaces espaciais entre a representação imagética e os fenômenos representados, cuja força homológica abriga um processo complexo de codificação que permite uma transposição "naturalizada" da tridimensionalidade do real para superfícies acolhedoras bidimensionais.

Esse processo complexo de codificação comporta um itinerário ocular que remonta ao Renascimento e que nos indica a dimensão epistêmica da fotografia calcada na estruturação convencional da imagem fixa, a qual, entre outros aspectos, contempla as articulações espaciais implicadas na produção e na leitura imagética. Nesse sentido, encarar a fotografia pela perspectiva lúdica do jogo interespacial ao mesmo tempo que nos permite a explicitação 
dos componentes dessa interespacialidade como substratos das interações humanas, expõe a própria condição estruturadora de tais componentes na revelação da própria natureza representadora da fotografia como superfície sensível que reflete o esforço humano de enxergar a si mesmo.

\section{Notas}

' Mesmo sendo considerado o inventor da fotografia, Nicéphore Niépce (17651833) não alcançou reconhecimento público. Coube a Louis Jacques Mandé Daguerre (1787-1857) aprimorar a descoberta do primeiro e ganhar notoriedade pela divulgação do seu invento - o daguerreótipo - em 19 de agosto de 1839, pela Academia de Ciências da França.

${ }^{2}$ ALMEIDA (1995, p. 40) argumenta que o instantâneo não apenas é acentuado pela existência da pose como, simultaneamente, ratifica que tudo está em pose, entrelaçando a mobilidade e o estático: "O instantâneo é a aceitaçāo rendida de que tudo está em pose tal como a pose é a admissão charmosa do transitório."

\section{Referências}

ALMEIDA, Bernardo Pinto de. Imagem da fotografia. Lisboa: Assírio \& Alvim. 1995.

AUMONT, Jacques. A Imagem. 2. ed. Campinas: Papirus, 1995.

BENJAMIN, Walter. A obra de arte na era de sua reprodutibilidade técnica. In: Magia e Técnica, Arte e Política. 4. ed. São Paulo: Brasiliense. 1988. p. 165-196.v. 1.

DUBOIS, Philippe Oato fotográfico e outros ensaios. 2. ed. Campinas: Papirus, 1998.

FLUSSER, Vilém. Filosofia da caixa preta: ensaios para uma futura fïlosofia da fotografia. São Paulo: Hucitec, 1985.

FRADE, Pedro Miguel. Figuras do espanto: a fotografia antes da sua cultura. Porto: Asa, 1992

FREUND, Gisèle. Fotografia e sociedade. 2. ed. Lisboa: Vega. 1995. (Col. Comunicação \& Linguagens).

HARVEY, David. Condição pós-moderna. São Paulo: Edições Loyola, 1993. LURIA, A. R. Curso de psicologia geral. 2 ed. Rio de Janeiro: Civ. Brasileira. 1991. v. 2: Sensações e percepção: psicologia dos processos cognitivos.

MACHADO, Arlindo. A ilusão especular: introdução à fotografia. São Paulo: Brasiliense/Funarte, 1984. 
SCHAEFFER, Jean-Marie. A imagem precária: sobre o dispositivo fotográfico. Campinas, SP: Papirus, 1996. (Col. Campo Imagético). 


\section{Assinaturas}

Contracampo ainda não possui serviço de assinaturas e é enviada gratuitamente às bibliotecas dos Programas de Pós-graduação e Faculdades Públicas de Comunicação do pais, através de mala direta.

Os interessados em adquirir números da revista podem solicitar diretamente ao Programa de Pós-graduação, utilizando-se do endereço eletrônico do editor: felipepena@globo.com ou através do seguinte endereço:

Rua Tiradentes, 148/Ingá - Niterói - CEP: 24270-240 Rio de Janeiro- RJ 


\section{NORMAS PARA PUBLICAÇÃO}

\section{Submissão de artigos}

Contracampo acolhe colaborações de autores do Brasil e do exterior, pertencentes ou não a programas de Comunicação. Os trabalhos submetidos são avaliados por dois pareceristas do Conselho Editorial e publicados após recomendação de ambos, obedecendo às datas de fechamento dos números semestrais. SOMENTEARTIGOS INÉDITOS PODERÃOSER SUBMETIDOS A CONTRACAMPO.

\section{Formato e preparação de artigos para submissão}

Os trabalhos submetidos devem possuir entre 5000 a 7000 palavras, ou de 13 a 15 laudas, digitadas em Word (ou similar), fonte Times New Roman, corpo 12. O formato da página adotado para os trabalhos é o A4 $(21 \times 29.7 \mathrm{~cm}) \mathrm{com}$ as seguintes medidas: $2 \mathrm{~cm}$ de margem superior; $3 \mathrm{~cm}$ de margem inferior, $5 \mathrm{~cm}$ de margem esquerda, $3 \mathrm{~cm}$ de margem direita e medianiz 0 . Cabeçalho de $1,2 \mathrm{~cm}$ e rodapé de $1,6 \mathrm{~cm}$. Alinhamento pela esquerda somente. 0 espaço entre linhas deve ser simples para o corpo do texto, e o espacejamento do parágrafo deve ser de 12 antes e 6 pontos depois de cada parágrafo, com recuo direito e esquerdo de valor 0 . Todos os parágrafos devem ser indentados em $0.5 \mathrm{~cm}$.

\section{Título e autoria}

Fonte Arial, negrito, corpo 12, centrado e espacejamento entre linhas de 1,5 linhas. Usar caixa-alta (letra maiúscula) apenas para a primeira letra do título do artigo, exceto para nomes próprios ou palavras que exijam o uso de caixa-alta por razões gramaticais. Onome do autor deve ser colocado abaixo da última linha do título, centrado, em Arial, itálico, corpo 10. Se o artigo possuir mais de um autor, separar os nomes destes com um vírgula e espaço. Se o número de autores exceder uma linha, não dividir o nome de um autor: coloque-o na linha seguinte. $O$ nome de cada autor deve estar na seguinte ordem: primeiro nome, segundo nome ou inicial (se for o caso) e o sobrenome.

Incluir no final da primeira página do artigo nota de rodapé (com entrada após o sobrenome de cada autor, numeração personalizada por asterisco) com dados biográficos sobre o(s) autor(es), constante de filiação institucional, titulação, etc. com cerca de 50 palavras, em fonteA rial, regular, corpo9.

\section{Palavras-chave e resumos}

As palavras-chaves e resumo em português devem vir após o título e nome dos autores. Usar 3 a 5 palavras-chaves, fonte Arial, corpo 10. Estas devem ser colocadas antes do resumo e serem antecedidas da palavra: "Palavras-chaves", alinhada à esquerda, em Arial, negrito, corpo 10. 
O resumo deve ter aproximadamente 150 palavras. Usar fonte Arial, corpo 10 para o resumo. As especificações para parágrafo e coluna são as mesmas do corpo do texto (siga as instruções dadas para margens, espacejamento, indentação, coluna e alinhamento). O resumo deve ter como título a palavra "Resumo", alinhada à esquerda, em Arial negrito, corpo 10. Na linha seguinte coloque o texto do resumo.

As palavras-chaves e resumo em inglês devem observar o mesmo formato para o português, sendo, porém, em itálico. Devem vir após o resumo em português. Substituir os títulos: "Palavras-chaves" por "Keywords" e "Resumo" por "Abstract" , para as palavras-chaves e resumo em inglês.

$\mathrm{O}$ texto do artigo deve ser iniciado na página seguinte às palavras-chaves (kevwords) e ao resumo (abstract) em inglês. Para tanto, inserir quebra de página entre a página com título, autoria, resumo e abstract e corpo do artigo. Não inserir numeração nas páginas.

\section{Subtitulos}

Sugerimos o uso de não mais de três níveis de subtítulos para seu artigo, os quais devem seguir estas especificações:

$\checkmark$ primeiro nível de subtítulo: Arial, negrito, corpo 11, alinhado à esquerda, espaço de parágrafo de 24 pontos antes do subtítulo e de 6 pontos após o subtítulo;

$\checkmark$ segundo nível de subtítulo: Arial, negrito, corpo 10, indentado em $0.5 \mathrm{~cm}$, espaço de parágrafo de 12 pontos antes do subtítulo e de 6 pontos após o subtítulo;

$\checkmark$ terceiro nível de subtítulo: Arial, negrito, itálico, corpo 10, indentado em $1.0 \mathrm{~cm}$, espaço de parágrafo de 12 pontos antes do subtílulo e de 6 pontos após o subtítulo.

Usar caixa-alta (letra maiúscula) apenas para a primeira letra do subtítulo do artigo, exceto para nomes próprios ou palavras que exijam o uso de caixa-alta por razões gramaticais. Inserir um parágrafo (Enter) entre o tex to que antecede o subtítulo e este.

\section{Imagens}

Para o envio de material fotográfico, os editores devem ser previamente contatados para maiores especificações.

\section{Citaçöes}

Para citar um autor no corpo do texto use 'aspas simples'. Citações que excedam três linhas devem ser separadas do corpo do texto (aperte a tecla 'enter' uma vez). Para citações, usar fonte Arial, regular, corpo 9. alinhamento à esquerda. Espacejamento entre linhas deve ser simples. recuo de parágrafo de $0.5 \mathrm{~cm}$, e espaço de 6 pontos após cada parágrafo de sua citação (se for o caso). 


\section{Notas}

Usar notas de final de documento apenas, com exceção da nota biográfica do(s) autor, que aparece na primeira página do artigo. Usar fonte Arial, regular, corpo 9; e alinhar o texto pela esquerda. Usar notas de rodapé quando absolutamente necessário e evitar notas longas. As notas devem ser numeradas consecutivamente ao longo do texto.

\section{Referências}

As referências bibliográficas devem vir logo após a seção de notas e seguir a NBR 6023 DA ABNT, observado o formato de margens e espaços definidos acima. Todas as referências devem vir listadas alfabeticamente e cronologicamente na seção de referências, sob o título "Referências" (ver especificações para títulos de primeiro nível). Para formatar as referências use fonte Times New Roman, regular, corpo 12, alinhamento à esquerda, espacejamento simples entre linhas, recuo especial de $0,5 \mathrm{~cm}$ da segunda linha em diante e espaço de parágrafo de 6 pontos após cada referência.

\section{Considerações sobre direitos autorais}

Os artigos submetidos devem vir acompanhados de autorização de publicação pelo autor. Contracampo detém o copyright sobre o conteúdo da publicação aceita. Fotocópias de artigos são autorizadas mediante solicitação aos editores e crédito das fontes.

222 Para evitar violação das leis de direitos autorais, favor não utilizar longas e muitas citaçồes de uma mesma fonte, ou figuras publicadas previamente sem um documento de autorização de uso dos direitos autorais. Isto também se refere a imagens produzidas pelo autor, publicadas em outro veículo, cujo direito autoral tenha sido transferido à editora referente ao veículo anterior. Autores que não fornecerem documentos de autorização de uso de direitos autorais terão seus artigos devolvidos.

\section{Envio de artigos}

Os originais deverão ser enviados em três cópias impressas, acompanhadas de disquete, para o seguinte endereço:

Rua Tiradentes, 148 , Ingá / Niterói CEP: 24.270-240

Rio de Janeiro- RJ

Contracampo - Uma revista financiada pelo programa PROAP/CAPES. e-mail para contato: felipepena@globo.com 


\section{3}

CONTRACAMPO 13 
225 



O hibridismo do cinema contemporâneo

Donnie Darko: Imagem, Tecnologias Digitais e Multimediação em um Filme entre o Underground e o Massivo

Adorno, Antonioni e Deleuze: um encontro inesperado

Quanto vale ou é por quilo? Imagens-máscara dos excluídos, da era braçal à digital

Dick Tracy, o filme high concept e o cinema brasileiro

Jean Cocteau: comunicação visual e imaginário mitopoiético

Moderna Lavoura Arcaica: a ambivalência estrutural no cinema de arte

\section{TELEVISÃO}

Televisão: entre a divulgação e a promoção

Nos limiares da visibilidade midiática: apontamentos sobre a cronossensologia

Acontecimento, memória e televisão

VJ em cena: espaços como partitura audiovisual

Analisando a autoria dos amores narrados nas telenovelas

\section{FOTOGRAFIA}

O artista contemporâneo e as novas possibilidades de produção da imagem na Fotografia

A Fotografia como jogo interespacial 